\title{
Antibody False Positivity Among COVID-19 Convalescent Plasma Donors: A Comparative Study from the Turkish Red Crescent Blood Center
}

\author{
๑ Levent Hayat, ๑ Can Murat Beker, ๑ Aziz Karaca* ๑ N Nurettin Hafizoglu*, \\ ๑ Kerem Kinik**, (๑) Fatma Meric Yilmaz ${ }^{* *},{ }^{* * *}$ \\ Aegean Regional Blood Centre, Turkish Red Crescent, Izmir, Turkey \\ *General Directorate of National Blood Services, Turkish Red Crescent, Ankara, Turkey \\ **Managing Board, Turkish Red Crescent, Ankara, Turkey \\ ***Yildirim Beyazit University Faculty of Medicine, Department of Basic Medical Sciences, Ankara, Turkey
}

\section{Abstract}

Aim: During our routine work at the Turkish Red Crescent (TRC) laboratories, human immunodeficiency virus (HIV) $1 / 2$ antibody false-positive results were observed among Coronavirus disease-2019 convalescent plasma (CP) donors more frequently than healthy donors. We aimed to determine anti-HIV 1/2 antibody false-positivity rates among the CP donors and healthy blood donors.

Methods: The present study was designed as a cross-sectional study which was a type of observational study. Total 3689 donations from 2593 donors donated CP to the TRC between 11 April-06 July 2020, were screened by electrochemiluminescence immunoassay for the presence of antibody against HIV $1 / 2$. The confirmation tests were performed with line immunoassay. All of the donors were non-remunerated CP donors between the ages of 18-60. For the control group, 411078 donations from 407363 healthy blood donors were received on the same days.

Results: Repeated reactivity rates (1.87\%) were significantly higher than the control group $(0.13 \%, p<0.05)$. However, there was not a statistically significant difference between the confirmed reactivity rates of the study group (0.03\%) and the control group $(0.01 \%$, $\mathrm{p}=0.217)$.

Conclusion: In our study, it was determined that the false-positive results obtained from serologic HIV screening tests of CP donors were significantly higher when compared to the healthy blood donors.

Keywords: False HIV, convalescent plasma, serologic tests, immunoassay

\section{Introduction}

As a virus from the coronavirus family, the Severe Acute Respiratory syndrome-Coronavirus-2 (SARS-CoV-2), which was firstly defined in Wuhan -a sub-provincial city in China- towards the end of 2019 and assumed to be transmitted to humans from bats, has spread very fast and taken effect on global health, economy and social behavior around the world at short notice. During the writing of this paper, it was denoted that millions of people were infected with the virus and it led to the death of almost four and half million people in 235 countries/ regions around the world (1). Naming the disease caused by this virus as Coronavirus disease-2019 (COVID-19) on 11 February 2020, World Health Organization (WHO) declared the outbreak as pandemic on 11 March 2020 (2).

There is no definite cure for the disease yet. The practice of $\mathrm{CP}$, which comes up as a treatment choice and is received from the recovered patients, is an acquired passive immunity treatment. CP was used as postexposure prophylactic for diseases such as viral hepatitis, measles, epidemic parotitis, and polio while it was used as the medical purpose for diseases such as influenza, bird influenza, SARS-CoV, Middle East Respiratory syndrome

Address for Correspondence: Aziz Karaca, General Directorate of National Blood Services, Turkish Red Crescent, Ankara, Turkey 
and Ebola (3-9). First practices related to the CP use in COVID-19 have come from the people's republic of China, the center of the disease. It was reported that the first $\mathrm{CP}$ was obtained in Wuhan on February $1^{\text {st }}, 2020$ and was given to a patient on February $9^{\text {th }}, 2020$ in this country (10). U.S. Food and Drug Administration (FDA) approved the use of the plasma received from people who were infected with and recovered from COVID-19 in the treatment of existing patients with a declaration of "COVID-19 Convalescence Research-Emergency" on March 24 ${ }^{\text {th }}, 2020$ (11). Following all these news, it was decided by the Republic of Turkey Ministry of Health that the CP can be used in the treatment of COVID-19 patients. As part of this, in order to start receiving CP donations, a call was made by the TRC to those, who recovered from the disease and met the requirements of being a donor.

In the serologic tests conducted on the CP donors at the TRC laboratories, it was observed that antihuman immunodeficiency virus (HIV) $1 / 2$ antibody was found to be false positive more often than other blood donors. In our study, it was aimed to show if there is any significant difference between the CP donors and healthy blood donors regarding the false positive HIV

\section{$1 / 2$ test positivity rates.}

\section{Methods}

\section{Study design}

The present study was designed as a cross-sectional study which was a type of observational study. This study was approved by the Turkish Red Crescent Ethical Committee (09.11.2020/2020-01). Total 3689 donations from 2593 donors, who donated CP to the TRC between 11 April-06 July 2020, were screened for the presence of anti-HIV $1 / 2$ antibody. All of the donors in the study group were between the ages of 18-60 (median age 21.5) and were the voluntary and non-remunerated $\mathrm{CP}$ donors. The study group consisted of 2361 males (91.1\%) and 232 females $(8.9 \%)$. The clinical symptoms of CP donors in study group resolved at least 14 days before donation and in 48 hours before they had negative SARS-CoV-2 polymerase chain reaction test results for last consecutive two tests. For the control group, the test results of 411078 donations from 407363 healthy blood donors who donated within the same period were used. The blood donors in control group were between the ages of 18-60 (median age 27). The control group consisted of 350724 male (86.1\%) and 56639 female (13.9\%). The high male to female ratio in both groups was seen because the TRC does not accept plasma donations of any kind from women with a pregnancy history, including miscarriages or $D / C$, due to the risk of transfusion-related acute lung injury in the recipient. All the donors in the study and

\begin{tabular}{|l|l|l|l|l|}
\hline \multicolumn{4}{|l|}{ Table 1. Demographic data of study and control groups } \\
\hline & \multicolumn{3}{|l|}{$\begin{array}{l}\text { Study group } \\
(\mathbf{n}=2593)\end{array}$} & \multicolumn{2}{l|}{$\begin{array}{l}\text { Control group } \\
(\mathbf{n}=407363)\end{array}$} \\
\cline { 2 - 5 } & Male & Female & Male & Female \\
\hline Number (\%) & $\begin{array}{l}2361 \\
(91.1)\end{array}$ & $\begin{array}{l}232 \\
(8.9)\end{array}$ & $\begin{array}{l}350724 \\
(86.1)\end{array}$ & $\begin{array}{l}56639 \\
(13.9)\end{array}$ \\
\hline $\begin{array}{l}\text { Median age } \\
\text { (min-max) }\end{array}$ & $21.5(18-60)$ & $27.0(18-60)$ \\
\hline Donation number & 3689 & 411078 \\
\hline
\end{tabular}

control groups gave the written consent before donation. These demographic data are summarized in Table 1.

As part of the infectious serologic screening tests of blood donors, the anti-HIV $1 / 2+$ p24 antigen tests were conducted on the electrochemiluminescence immunoassay (eCLIA) method and via the Cobas 8000 e801 (Roche, Germany) device and Elecsys HIV Duo (Roche, Germany) kits. In accordance with our test algorithm, the samples determined to be reactive in the first test were studied twice more and the results found to be reactive in at least two of three studies, were considered as "repeatedly reactive".

The confirmation tests were studied with the line immunoassay (LIA) method and via Auto-LIA 48 (Fujirebio, Belgium) device and INNO LIA HIV I/II score kits for the samples which were found to have repeated reactivity

\section{Statistical Analysis}

The data that used in our study were received from the digital archives of the TRC. The universe of our study consists of voluntary COVID-19 CP and healthy blood donors. The power of our cross-sectional study was calculated as $100 \%$. For the statistical comparison of the reactivity rates of these two groups, Mid-P Exact test was used through OpenEpi v3.01 program, because it was recommended by the software for the actual distribution of data. The flow chart of the study is demonstrated on Figure 1.

\section{Results}

Sixty-nine $(1.87 \%)$ of 3689 CP donations in the study group were found to have repeatedly reactive for antiHIV $1 / 2$ in the serologic tests. The confirmation test was negative (false positivity) in 68 donations $(1.84 \%)$ among $\mathrm{CP}$ donors and 9 of them were female $(0.35 \%), 59$ of them were male (2.28\%). In the study group confirmation test was positive (true HIV infection) in one male donor $(0.03 \%)$. In the control group, $520(0.13 \%)$ of 411078 blood donations were found to have repeated reactivity for HIV $1 / 2$ antibodies in the serologic tests. The confirmation test was negative in $461(0.12 \%)$, positive in 49 (0.012\%) and indeterminate in $10(0.002 \%)$ of them. In the control group, $84(0.021 \%)$ of unconfirmed donors were female 


\section{$3689 \mathrm{CP}$ donations}

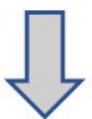

\section{9 donations were repeated reactive for anti-HIV $1 / 2+p 24$}



\section{Confirmation test was positive in 1 donation}

\section{Confırmation tests were negative in 68 donations}

Figure 1. Flow chart of study

and 377 (0.093\%) were male.

When the repeated reactivity rates of the study group $(1.87 \%)$ and control group $(0.13 \%)$ were compared, the difference was found to be statistically significant $(p<0.05)$.

When the confirmed reactivity rates of the study group $(0.039 \%)$ and the control group $(0.012 \%)$ were compared, the difference was not statistically significant $(p=0.217)$. In our study, any confirmed female donor was detected. Because of this reason, statistical comparison between genders was not calculated in the confirmed study group.

When the unconfirmed reactivities found in the study group (1.84\%) and in the control group (0.12\%) were compared, the difference was found to be statistically significant $(p<0.05)$. In unconfirmed group, difference between female - male donors rates of the study group $(0.35 \%$ and $2.28 \%$, respectively) and control group $(0.021 \%$ and $0.093 \%$, respectively) were statistically significant $(p<0.05)$. The findings are summarized in Table 2,3 .

\section{Discussion}

The findings of our study support our hypothesis that COVID-19 patients might have a more false positive anti-HIV $1 / 2$ test result than healthy blood donors in the serological methods. In our study, we found that false positivity rate in male donors was significantly higher than female donors. We think that this difference resulted from low number of female donors in study and control groups. Serologic tests for HIV 1/2, hepatitis B, C virus and syphilis are performed by the TRC to the plasma received from the $\mathrm{CP}$ donors due to biosafety reasons. As is known, in the tests based on the antigen-antibody interaction principle, cross-reactivity can be seen since the binding domain of each antibody or the molecular association may interact with more than one antigenic determinant or more than one antigen, respectively. In other words, the cross-

\begin{tabular}{|l|l|l|l|}
\hline Table 2. Anti-HIV 1/2 reactivities of the CP and blood donations \\
\hline & $\begin{array}{l}\text { CP donations } \\
\text { (n=3689) }\end{array}$ & $\begin{array}{l}\text { Blood } \\
\text { donations } \\
\mathbf{( n = 4 1 1 0 7 8 )}\end{array}$ & $\mathbf{p}^{*}$ \\
\hline Repetitive reactivity \% (n) & $1.87(69)$ & $0.13(520)$ & $<0.05$ \\
\hline Confirmed \% (n) & $0.03(1)$ & $0.012(49)$ & 0.217 \\
\hline Unconfirmed \% (n) & $1.84(68)$ & $0.12(461)$ & $<0.05$ \\
\hline Indeterminate \% (n) & 0 & $0.002(10)$ & - \\
\hline $\begin{array}{l}\text { *Mid-P exact test was used for comparison of two groups, HIV: Human } \\
\text { immunodeficiency virus, CP: Convalescent plasma }\end{array}$ \\
\hline
\end{tabular}

\begin{tabular}{|l|l|l|l|}
\hline \multicolumn{5}{|l|}{ Table 3. Unconfirmed anti-HIV 1/2 test results related to gender } \\
\hline & Male \% (n) & Female \% (n) & $\mathbf{p}^{\text {* }}$ \\
\hline CP donors ( $\mathbf{n = 2 5 9 3 )}$ & $2.28(59)$ & $0.35(9)$ & $<0.05$ \\
\hline $\begin{array}{l}\text { Blood donors } \\
\text { (n=407363) }\end{array}$ & $0.093(377)$ & $0.021(84)$ & $<0.05$ \\
\hline $\begin{array}{l}\text { *Mid-P exact test was used for comparison of two groups, HIV: Human } \\
\text { immunodeficiency virus, CP: Convalescent plasma }\end{array}$ \\
\hline
\end{tabular}

reactivity can occur because of the antigen that shares single epitope or of the structural similarity of epitopes (12).

In the tests based on the SARS-CoV antigen-antibody interaction, cross-reactions similar to this can also be observed. For example, it was reported that dual antigenic cross-reactivity with $\mathrm{N}$ proteins was seen between SARSCoV and swine group 1 CoVs [TGEVs (M6 and P115 and PRCV-ISU1] in a study conducted (13). Accordingly, there are studies showing that auto-antibodies in some autoimmune diseases can cross-react with the nucleocapsid protein of SARS-CoV and cause false positivity $(14,15)$. Also, false positivities due to cross-reaction have been found between SARS-CoV and HCoV-229E \& HCoV-OC43, which are among the other coronaviruses that cause common cold in humans (16). Similar cross-reactions have been observed for Human T-lymphotropic virus (HTLV) I 
and II, which rank among the Retroviridae family just like HIV $1 / 2$. It was suggested that these reactions can be associated with rgp46-1 and rgp46-2 antigens of HTLV-I and GD21, p19, p24, gp21 and gp46 antigens of HTLV-II (17). In a study conducted by Pradhan et al. (18), it was stated that the amino acid array of four domains located on the SARS-CoV-2 S glycoprotein shows similarity with HIV-1 gp 120 and gag glycoproteins. Finally Mannar et al. (19) reported that host-derived glycans on spike proteins displayed high levels of cross-reactivity with anti-HIV 1 gp120 antibodies. These findings support the idea that the significantly high false reactivity rate we encountered results from the similarity of antigenic epitopes. The false positive test results for anti-HIV $1 / 2$ were reported with another device system that used eCLIA test method. Tan et al. (20) and Papamanoli and Prevdos (21) reported three acutely ill COVID-19 patients had false positive anti-HIV tests. In these patients negative test results were detected with repeated serologic tests with different devices and and with molecular techniques.

\section{Study Limitations}

The main limitation of our study was that only one device and kit system developed by one company was used in our study. The second limitation of our study was low percentage of female donors in study and control groups ( $8.9 \%$ and $13.9 \%$, respectively), so our results are not generalizable to both genders. The third limitation of our study was indeterminate confirmation test results and difficulty of follow-up sample obtaining.

\section{Conclusion}

Despite these limitations our test systems are safe and accepted worldwide, due to the national blood-banking algorithm of our country. We think that the results of this study warn us to be careful about the serological HIV $1 / 2$ tests for the COVID-19 patients. Because the number of patients who had experienced COVID-19 and recovered has been increasing day by day; false-positive anti-HIV $1 / 2$ results might increase in hospital settings. HIV $1 / 2$ serological tests are being ordered for many screening purposes so this cross-reactivity might be a real problem. It is needed to be investigated and reported for different device and kit systems. It seems that the manufacturers will need to study on and solve this cross-reactivity problem to avoid false positive results. We think that difference of false positivity rates between genders needs new studies including a higher female population than our study.

False-positive results in anti-HIV $1 / 2$ tests might be observed in the patients recovered from COVID-19. Defined cross-reactivity should be taken into account both in blood banking, CP treatment process and routine clinical practice.

\section{Authorship Contributions}

Concept: L.H., C.M.B., A.K., N.H., K.K., F.M.Y., Design: L.H., C.M.B., A.K., N.H., K.K., F.M.Y., Data Collection or Processing: L.H., C.M.B., Analysis or Interpretation: L.H., C.M.B., A.K., Literature Search: L.H., C.M.B., Writing: L.H., C.M.B.

Conflict of Interest: No conflict of interest was declared by the authors.

Financial Disclosure: The authors declared that this study received no financial support.

\section{References}

1. World Health Organization (2020). Coronavirus disease (COVID-19) pandemic page [online]. Available from: https://www.who.int/emergencies/diseases/novelcoronavirus-2019. Accessed August 18, 2021.

2. World Health Organization (2020). Rolling updates on coronavirus disease (COVID-19). Available from: https://www. who.int/emergencies/diseases/novel-coronavirus-2019/ events-as-they-happen. Updated July 31, 2020. Accessed August 23, 2021.

3. Casadevall A, Scharff MD. Return to the past: the case for antibody-based therapies in infectious diseases. Clin Infect Dis 1995;21:150-61.

4. Stokes J, Jr, Wolman Ij, Carpenter Hc, Margoliis J. Prophylactic Use of Parents' Whole Blood in Anterior Poliomyelitis: Philadelphia Epidemic Of 1932. Am J Dis Child 1935;50:58195. doi:10.1001/archpedi.1935.01970090011002

5. Hung IF, To KK, Lee CK, et al. Convalescent plasma treatment reduced mortality in patients with severe pandemic influenza A (H1N1) 2009 virus infection. Clin Infect Dis 2011;52:44756.

6. Zhou B, Zhong N, Guan Y. Treatment with convalescent plasma for influenza A (H5N1) infection. N Engl J Med 2007;357:1450-1.

7. Zhang JS, Chen JT, Liu YX, et al. A serological survey on neutralizing antibody titer of SARS convalescent sera. J Med Virol 2005;77:147-50.

8. Ko JH, Seok H, Cho SY, et al. Challenges of convalescent plasma infusion therapy in Middle East respiratory coronavirus infection: a single centre experience. Antivir Ther 2018;23:617-22.

9. World Health Organisation. Use of convalescent whole blood or plasma collected from patients recovered from Ebola virus disease (2014). Available from: https://www.who.int/csr/ resources/publications/ebola/convalescent-treatment/en/. Accessed August 25, 2021.

10. Xinhua. China puts 245 COVID-19 patients on convalescent plasma therapy available from: http://www.xinhuanet.com/ english/2020-02/28/c_138828177.htm. Accessed August 25, 2021. 
11. CBER. Investigational COVID-19 Convalescent Plasma Emergency INDs. Avaliable from: https://www.fda.gov/ vaccines-blood-biologics/investigational-new-drug-ind-ordevice-exemption-ideprocess-cber/investigational-covid-19convalescent-plasma-emergency-inds. Accessed March 24, 2020.

12. University of South Carolina. Immunoloji - Bölüm Yedi Immunoglobülin- Antijen-Antikor Reaksiyonlari ve Seçilmiş Testler (in Turkish) available from: https:// www.microbiologybook.org/Turkish-immunol/ immunolchapter7turk.htm. Accessed August 25, 2021.

13. Vlasova AN, Zhang $X$, Hasoksuz $M$, et al. Two-way antigenic cross-reactivity between severe acute respiratory syndrome coronavirus (SARS-CoV) and group 1 animal CoVs is mediated through an antigenic site in the $\mathrm{N}$-terminal region of the SARS-CoV nucleoprotein. J Virol 2007;81:13365-77.

14. Wang YS, Shen H, Sun SH, et al. Analysis of False-Positive Associated with Antibody Tests for SARS-CoV in SLE Patients. Shi Yan Sheng Wu Xue Bao 2003;36:314-7. [Abstract] Since the article language is in Chinese, it is cited from abstract.

15. Wang $Y$, Sun $S$, Shen $H$, et al. Cross-reaction of SARS-CoV antigen with autoantibodies in autoimmune diseases. Cell Mol Immunol 2004;1:304-7.

16. Che $X Y$, Qiu LW, Liao $Z Y$, et al. Antigenic cross-reactivity between severe acute respiratory syndrome-associated coronavirus and human coronaviruses 229E and OC43. J Infect Dis 2005;191:2033-7.

17. Tsao KC, Chen GW, Huang CG, et al. False positive antibody results against human T-cell lymphotropic virus in patients with severe acute respiratory syndrome. J Med Virol 2005;77:3316.

18. Pradhan P, Pandey AK, Mishra A, et al. Uncanny similarity of unique inserts in the 2019-nCoV spike protein to HIV-1 gp120 and Gag. BioRvix 2020. doi.org/10.1101/2020.01.30.927871

19. Mannar D, Leopold K, Subramaniam S. Glycan reactive antiHIV-1 antibodies bind the SARS-CoV-2 spike protein but do not block viral entry. Sci Rep 2021;11:12448.

20. Tan SS, Chew KL, Saw S, Jureen R, Sethi S. Cross-reactivity of SARS-CoV-2 with HIV chemiluminescent assay leading to false-positive results. J Clin Pathol 2021;74:614.

21. Papamanoli A, Psevdos G. False-positive HIV screening test in a patient with pulmonary embolism because of severe acute respiratory syndrome coronavirus 2 infection. AIDS 2021;35:1521-2. 